\title{
A lectin cytochemical study of glycoconjugates in the human retina
}

\author{
Kivelä, Tero Tapani
}

1987

Kivelä , T T \& Tarkkanen , A 1987 , ' A lectin cytochemical study of glycoconjugates in the human retina ' , Cell and Tissue Research , vol. 249 , no. 2 , pp. 277-288 . < http://www.springerlink.com/content/l8w71487716t888u/fulltext.pdf >

http://hdl.handle.net/10138/153584

publishedVersion

Downloaded from Helda, University of Helsinki institutional repository.

This is an electronic reprint of the original article.

This reprint may differ from the original in pagination and typographic detail.

Please cite the original version. 


\title{
A lectin cytochemical study of glycoconjugates in the human retina
}

\author{
Tero Kivelä and Ahti Tarkkanen \\ Department of Ophthalmology, Helsinki University Central Hospital, Helsinki, Finland
}

\begin{abstract}
Summary. The binding to morphologically normal human retina of eleven biotin- or peroxidase-coupled lectins with different carbohydrate specificities was studied. Eight formalin-fixed and paraffin-embedded eyes were examined. Photoreceptor cells bound Lens culinaris (LCA), wheat germ (WGA), peanut (PNA) and Ricinus communis (RCAI) agglutinins, and concanavalin A (ConA). The outer segment region was labeled more strongly than the inner segment region, and PNA labeled only cones. All these lectins except PNA bound to both plexiform layers, and all but PNA and RCAI to the nuclear layers. Pretreatment with neuraminidase to remove sialic acid resulted in increased binding of RCAI and PNA, which now labeled both rods and cones, and in decreased binding of WGA. Bandeiraea simplicifolia (BSAI), Dolichos biflorus (DBA), soybean (SBA), Ulex europaeus (UEAI), and Lotus tetragonolobus (LTA) agglutinins, as well as pokeweed mitogen (PWM) reacted only with retinal vascular endothelial cells, which were also labeled with the other lectins. The results indicate that $\alpha$-mannose, $\alpha$-glucose, $\beta$-galactose, $\mathrm{N}$-acetyl-D-glucosamine and $\mathrm{N}$-acetylneuraminic acid are present in glycoconjugates of human neuroretina.
\end{abstract}

Key words: Retina - Glycoconjugates - Lectin cytochemistry - Neuraminidase - Human

Lectins are a structurally very heterogeneous group of glycoproteins that have a common property of binding to specific carbohydrate residues (Goldstein and Hayes 1978). Most lectins currently in widespread use are derived from different plant species (see Table 1), but other lectins are present in various invertebrates and higher animals (Barondes 1984). Lectins have numerous applications in biomedical research, one of which is the demonstration of glycoconjugates in routinely processed histological specimens by lectin cytochemical and lectin fluorescence techniques (Leathem and Atkins 1983; Schwechheimer et al. 1984; Kessimian et al. 1986; Virtanen et al. 1986).

Binding of lectins to the retinae of various animal species has been reported in over twenty previous studies. These have centered on photoreceptor cells in order to understand the shedding and phagocytosis of their outer segments in normal and diseased conditions (Hall and Nir

Send offprint requests to: Tero Kivelä, M.D., Melkonkatu 3 B 29, SF-00210 Helsinki, Finland
1976; Nir and Hall 1979; McLaughlin and Wood 1980) and to study the selective binding of peanut agglutinin to cone photoreceptors (Blanks and Johnson 1984; Johnson et al. 1986; Kawano et al. 1984a, b). Lectin binding to other retinal layers has been studied in chicken, mouse and monkey (Bee 1982 b; Blanks and Johnson 1983; Uehara et al. $1983 \mathrm{a}, 1985$ ). As regards the human retina, however, only the binding of peanut and Ricinus communis (RCAI) agglutinins have been examined in detail (Blanks and Johnson 1984). The present study was undertaken to determine which layers of the human retina bind eleven commonly used lectins with different carbohydrate specificities, and to compare the results with previous reports from other species. The effect of neuraminidase treatment (Uehara et al. 1985) on the lectin binding pattern was also examined.

\section{Materials and methods \\ Histological specimens}

Three formalin-fixed and paraffin-embedded normal human eyeglobes enucleated from patients with an orbital tumor (age 52-59 years), one normal human eyeglobe manually enucleated by a psychotic patient (age 22 years), and four human eyeglobes containing a medium-sized malignant choroidal melanoma (patient age 60-71 years) were selected from the files of the Ophthalmic Pathology Laboratory, Department of Ophthalmology, Helsinki University Central Hospital. The case histories were reviewed to ascertain that any preoperative radiation therapy or treatment with cytostatic drugs had not been given. In one melanoma case, the retina adjacent to the tumor had been treated with an argon laser, but the other three melanomas had not received any preoperative treatment. In addition, retinal detachment was not present in any one case before enucleation. The blood groups of six patients (four of group A, two of group $O)$ could be retrieved from the case histories. Sections $(5 \mu \mathrm{m}$ thick) were cut from the specimens and mounted on chromium-gelatin-treated glass slides to ensure adherence $(0.05 \mathrm{~g}$ potassium chromium(III)sulphate dodecahydrate and $0.5 \mathrm{~g}$ gelatin in $100 \mathrm{ml}$ distilled water).

\section{Lectin cytochemistry}

The lectin cytochemical staining to demonstrate glycoconjugates in formalin-fixed and paraffin-embedded tissues was carried out using a commercial version (Vectastain $A B C$ 
Table 1. Origin, abbreviation, and sugar specificities for various lectins that have been used to study glycoconjugates of the retina

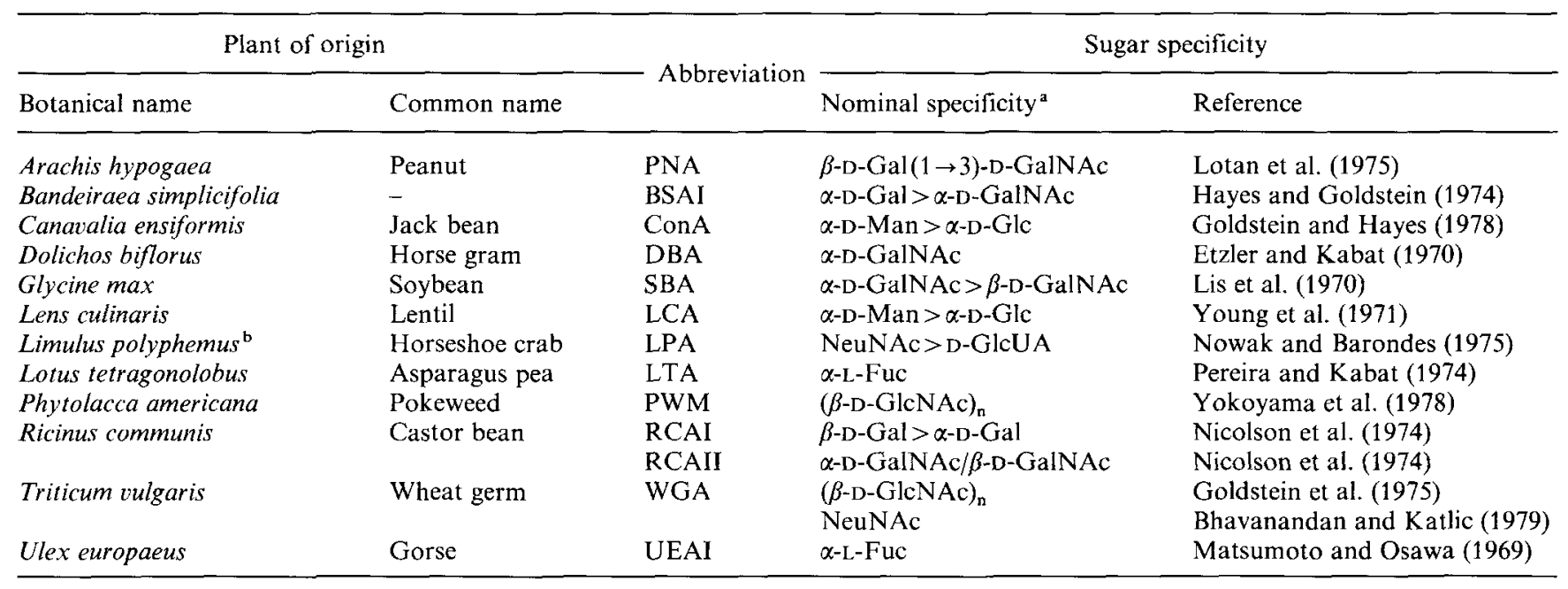

a Glc glucose, Man mannose, Gal galactose, Fuc fucose, GlcNAc N-acetylglucosamine, GalNAc N-acetylgalactosamine, NeuNAc Nacetylneuraminic acid, and GlcUA glucuronic acid

${ }^{b}$ An invertebrate species

Standard Kit, Vector Laboratories, Burlingame, California, USA) of the avidin-biotinylated peroxidase (ABC) method (Hsu and Raine 1982).

The sections were routinely deparaffinized in xylene and hydrated in an ethanol series. Endogenous peroxidase activity was destroyed by treatment for $30 \mathrm{~min}$ in $200 \mathrm{ml}$ methanol, containing $3.2 \mathrm{ml}$ of $30 \%$ hydrogen peroxide. Sections were washed in phosphate-buffered saline (PBS, pH 7.4) for three $10 \mathrm{~min}$ changes, then incubated with $2 \%$ bovine serum albumin (BSA; E. Merck, Darmstadt, FRG; diluted with PBS) in a moist chamber for $30 \mathrm{~min}$ at room temperature, to reduce non-specific binding of protein. Preliminary stainings demonstrated that changing the buffer to Tris (pH 7.6), supplemented with $1.0 \mathrm{mM} \mathrm{Mg}^{2+}, \mathrm{Ca}^{2+}$ - and $\mathrm{Mn}^{2+}$-ions, or omission of the methanol-hydrogen peroxide-treatment (Leathem and Atkins 1983) did not enhance the positive reaction.

Agglutinins (Table 1) from Arachis hypogaea (PNA, Peanut agglutinin, Lot 14F-8105-1), Bandeiraea simplicifolia (Agglutinin I, BSAI, Lot 34F-9685-1), Canavalia ensiformis (ConA, Concanavalin A, Lot 62F-3934), Dolichos biflorus (DBA, Lot 103F-9615-1), Glycine max (SBA, Soybean agglutinin, Lot 124F-9510), Lens culinaris (LCA, Lot 103F-8105), Lotus tetragonolobus (LTA, Lot 24F-9645-1), Phytolacca americana (PWM, Pokeweed mitogen, Lot 65F9580), Triticum vulgaris (WGA, Wheat germ agglutinin, Lot 45F-9615) and Ulex europaeus (Agglutinin I, UEAI, Lot 24F-9505-1) conjugated to biotin, and Ricinus communis agglutinin I (RCAI, Lot 34F-4028) conjugated to horseradish peroxidase were commercially obtained (Sigma Chemical Co., St. Louis, Missouri, USA), diluted with PBS to a protein concentration of $500 \mu \mathrm{g} / \mathrm{ml}$, and stored at $-20^{\circ} \mathrm{C}$ until needed.

The lectins were used at a protein concentration of $25 \mu \mathrm{g} / \mathrm{ml}$ (LCA, LTA, RCAI and SBA) and $50 \mu \mathrm{g} / \mathrm{ml}$ (the other lectins), diluted with PBS containing $2 \%$ BSA as a protein carrier. Parallel control sections were processed using lectins that had been preincubated for $30 \mathrm{~min}$ at room temperature with the corresponding hapten sugar inhibitors, used at a concentration of $0.2 \mathrm{~mol} / \mathrm{l}$. The hapten sugars
(Sigma) were D-galactose (PNA), $\alpha$-methyl-D-galactoside (BSAI), $\mathrm{N}$-acetyl-D-galactosamine (DBA and SBA), N-acetyl-D-glucosamine (PWM and WGA), $\alpha$-methyl-D-mannoside (ConA and LCA), $\alpha$-L-fucose (LTA and UEAI), and $\alpha$-lactose (RCAI). The sections were incubated with the lectin or the lectin-hapten complex in a moist chamber at $37^{\circ} \mathrm{C}$ for $90 \mathrm{~min}$.

The avidin-biotinylated peroxidase $(\mathrm{ABC})$ complex was prepared 30 min prior to use by mixing $32 \mu$ l of avidin $\mathrm{DH}$ (Vectastain $A B C$ Kit) and $32 \mu \mathrm{l}$ of biotinylated horseradish peroxidase (Vectastain ABC Kit) in $4.0 \mathrm{ml}$ PBS-BSA. After three washes in PBS, the sections were incubated with the $\mathrm{ABC}$ complex in a moist chamber at $37^{\circ} \mathrm{C}$ for $30 \mathrm{~min}$. Treatment with the $\mathrm{ABC}$ complex was omitted when $\mathrm{RCAI}$ was used, as this lectin was directly conjugated to horseradish peroxidase. Following three washes in PBS, the specific colour reaction was developed with $40 \mathrm{mg}$ of 3-amino-9ethylcarbazole (Sigma; diluted in $12 \mathrm{ml}$ of N,N-dimethylformamide, E. Merck) in an acetate buffer $(35.2 \mathrm{ml}$ of $0.2 \mathrm{M}$ sodium acetate, $14.8 \mathrm{ml}$ of $0.2 \mathrm{M}$ acetic acid and $150 \mathrm{ml}$ of distilled water, final pH 5.0) containing $200 \mu \mathrm{l}$ of $30 \%$ hydrogen peroxide. Coverslips were mounted with Aquamount (BDH Chemicals Ltd., Poole, England).

\section{Enzyme digestions}

Duplicate series with hapten-inhibition controls were stained after neuraminidase treatment to expose penultimate carbohydrate residues blocked by sialic acid (Uehara et al. 1985), or after slight proteolytic digestion to enhance the availability of lectin binding sites in formalin-fixed and paraffin-embedded tissue (Leathem and Atkins 1983; Virtanen et al. 1986).

After deparaffinization and rehydration, the sections were washed three times in PBS and once in the acetate buffer. Neuraminidase (EC 3.2.1.18) from Clostridium perfringens (Type V, Sigma, Lot 63F-8172) was used at a concentration of $0.5 \mathrm{U} / \mathrm{ml}$ (substrate: N-acetylneuraminlactose) diluted in the acetate buffer containing $2 \%$ BSA. The sections were briefly covered with the same diluent, 
which was then blotted off, and incubation with the enzyme preparation carried out in a moist chamber at $37^{\circ} \mathrm{C}$ for $30 \mathrm{~min}$. Other sections were deparaffinized, rehydrated, washed in PBS and treated with $0.4 \%$ pepsin (E. Merck, Darmstadt, FRG) in $0.01 \mathrm{~N}$ hydrochloric acid at $37^{\circ} \mathrm{C}$ for $45 \mathrm{~min}$. Finally, the specimens were washed in PBS and staining with lectins carried out as described above.

\section{Results}

Sections stained with haematoxylin and eosin revealed well preserved retina in every specimen. In all eyeglobes the retina had become detached during processing, however, and there was some edema in the outer plexiform layer. With minor variations, lectin binding to all specimens was found to be identical. Table 2 summarises the results and compares them to previous findings in other species.

\section{Glucosyl- and mannosyl-specific lectins}

Concanavalin A (ConA). Without any pretreatment, ConA bound to all layers and vascular endothelia of human neuroretina (Fig. 1 A). The ganglion cell bodies and the region of photoreceptor outer segments were most intensely labeled, while the inner segment region, and both nuclear and plexiform layers reacted less intensely with ConA. The outer limiting membrane region, where the fibre baskets of Müller's cells are situated between photoreceptor inner segments, was distinctly labeled. Cross-sections of photoreceptor cells at the level of the inner segments showed that ConA preferentially outlined the surfaces of rods and cones (Fig. 1D). Weak positive reaction was also seen in their interior and in interphotoreceptor matrix filling the gaps between rod inner segments. The retinal pigment epithelium and most extraretinal tissues were also ConA-positive. Pepsin treatment enhanced the binding intensity throughout the retina (Fig. 1 B). Digestion with neuraminidase did not affect binding of ConA to the retina (Fig. 1C). Preincubation of ConA with $\alpha$-methyl-D-mannoside completely abolished the positive reaction.

Lens culinaris agglutinin ( $L C A$ ). Binding of LCA to untreated, pepsin-treated, and neuraminidase-treated retinas was basically identical to that of ConA. The background staining in untreated sections was, however, significant, but it was diminished after treatment with pepsin (Fig. 1E) or neuraminidase. The nuclear layers and, in particular, the outer limiting membrane region were less intensely labeled with LCA than with ConA. The positive reaction was inhibitable by preincubation with $\alpha$-methyl-D-mannoside.

\section{$N$-acetylglucosaminyl-and sialyl-specific lectins}

Wheat germ agglutinin (WGA). Without pretreatment, WGA bound strongly to ganglion cell bodies and to the outer segment region of photoreceptor cells, and less intensely to their inner segment region, and to both nuclear and plexiform layers. The outer limiting membrane was labeled in a beaded pattern (Fig. 2A). In a oblique section through photoreceptor inner segments, WGA bound preferentially to the gaps between the inner segments, and only weakly outlined surfaces of rods and cones (Fig. 2D). Staining of retinal vascular endothelial and extraretinal connective tis- sue cells was prominent. Treatment with pepsin slightly enhanced the binding of WGA to other retinal elements than photoreceptor cells, the labeling intensity of which was slightly reduced, partly as a result of mechanical loss of outer segments (Fig. 2B). After neuraminidase treatment, very reduced levels of WGA binding were seen throughout the retina, but notable positive reaction persisted in vascular endothelia and, inconsistently, in photoreceptor outer segments (Fig. 2C). The positive label in the retinal pigment epithelium was also abolished. Preincubation of WGA with $\mathrm{N}$-acetyl-D-glucosamine inhibited the positive reaction in all retinal layers, and greatly reduced it in vascular endothelia.

Pokeweed mitogen ( $P W M$ ). In all specimens, PWM bound only to vascular endothelial cells. This binding was moderately enhanced after neuraminidase treatment (Fig. 2E), and substantially decreased after preincubation of the lectin with $\mathrm{N}$-acetyl-D-glucosamine.

\section{Galactosyl-specific lectins}

Peanut agglutinin $(P N A)$. The peanut lectin preferentially bound to the region of cone inner and, in lesser extent, outer segments (Fig. 3A, E). Without any pretreatment, however, only a part of cones was positive. PNA also labeled goblet cells of the conjunctiva and the corneal endothelium. Pepsin treatment enhanced binding of PNA, and most cones became labeled. At the posterior pole it was even difficult to exclude labeling of occasional rods in some specimens (Fig. 3B, G). In oblique sections through the inner segments of photoreceptor cells, positive reaction was observed around cone inner segments, while their interior remained negative (Fig. 3D). Prominent increase in binding of PNA was seen after treatment with neuraminidase (Fig. 3C). The region of photoreceptor outer segments was intensely labeled, and the inner segment region of both rods and cones also reacted with PNA (Fig. $3 \mathrm{~F}, \mathrm{H}$ ). In addition, positive reaction was seen in both plexiform layers, in the retinal pigment epithelium and in many extraretinal tissues, whereas the nuclear layers remained negative. Preincubation of PNA with D-galactose resulted in a negative reaction.

Ricinus communis agglutinin I (RCAI). Before enzymatic digestion, RCAI bound strongly to vascular endothelial cells and to the region of photoreceptor outer segments, while the inner segment region remained negative, except for weak labeling near the outer limiting membrane (Fig. 4A). Both plexiform layers were weakly labeled, and the nuclear layers were negative. The corneal endothelial cells, goblet cells of the conjunctiva, the nonpigmented ciliary epithelium and many other extraretinal tissues were also labeled. Treatment with pepsin moderately enhanced the positive reaction in all retinal layers (Fig. $4 \mathrm{~B}$ ). The inner segment region was weakly labeled and, interestingly, this reaction seemed to be predominantly associated with cones, the cell bodies of which also sometimes bound RCAI in the outer nuclear layer, immediately adjacent to the outer limiting membrane (Fig. 4D). After neuraminidase treatment, the binding of RCAI was enhanced in all retinal layers, except in the region of photoreceptor inner segments (Fig. 4C). Both nuclear layers were positively labeled, and no preferential labeling of cones could be observed. Prein- 


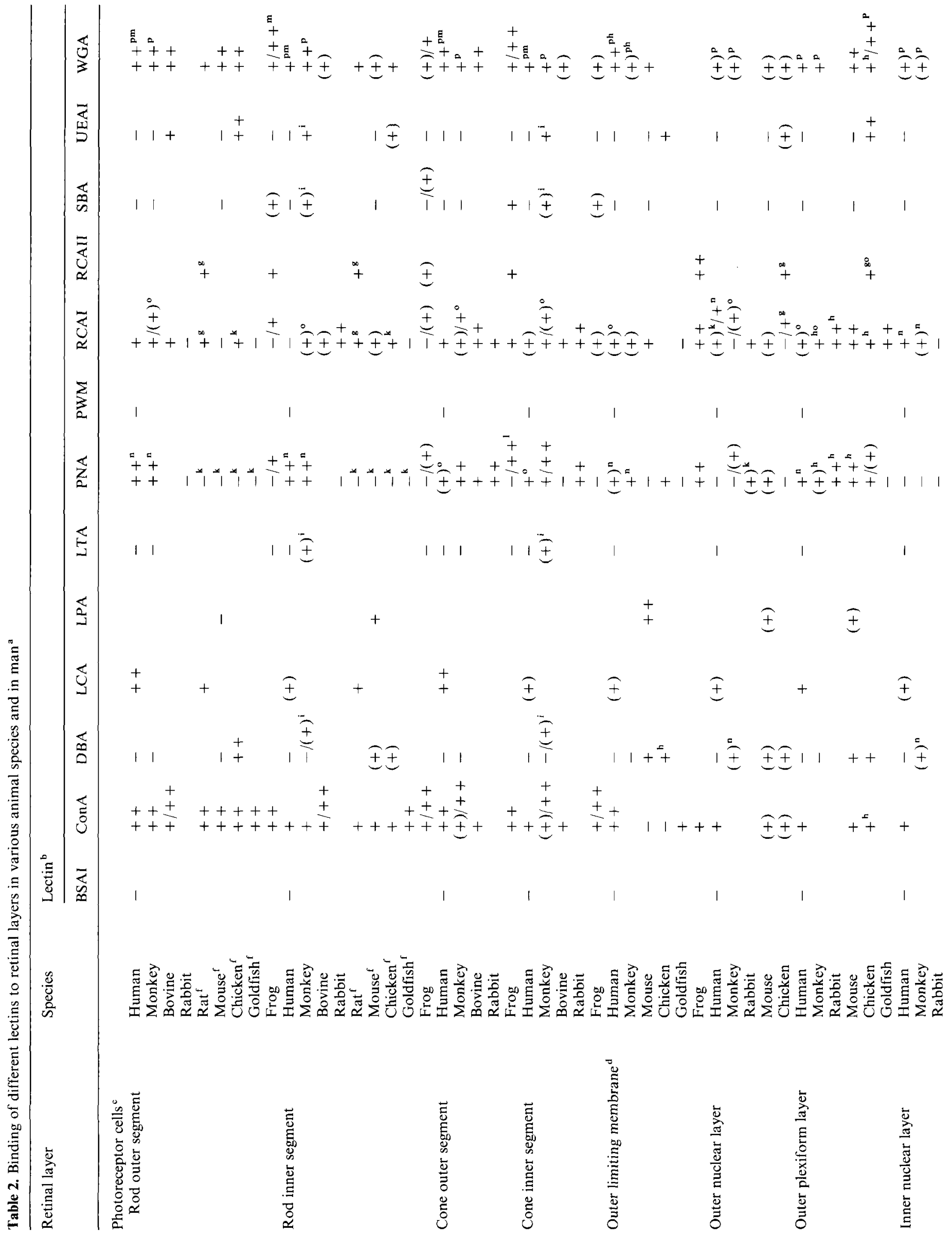




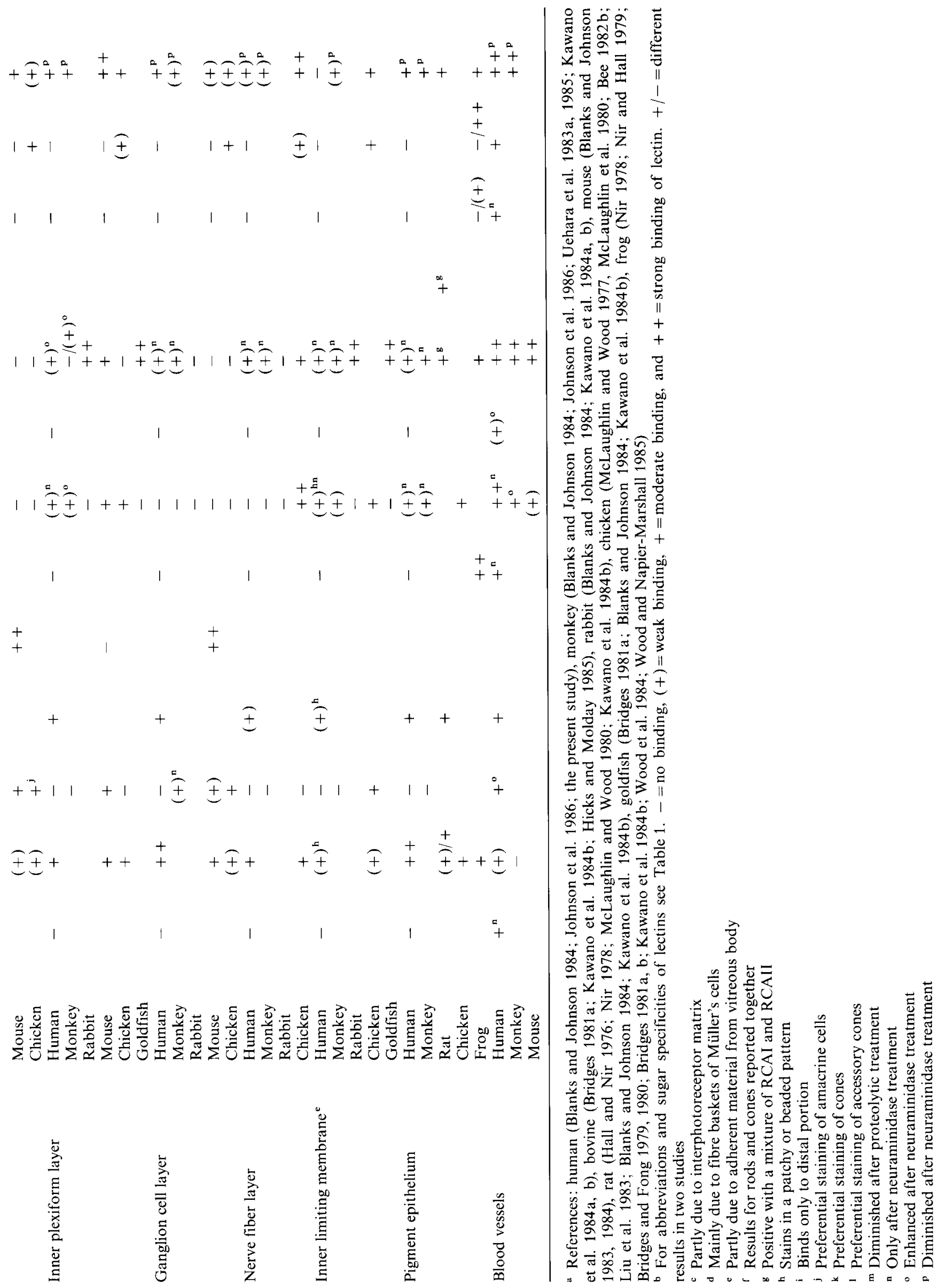




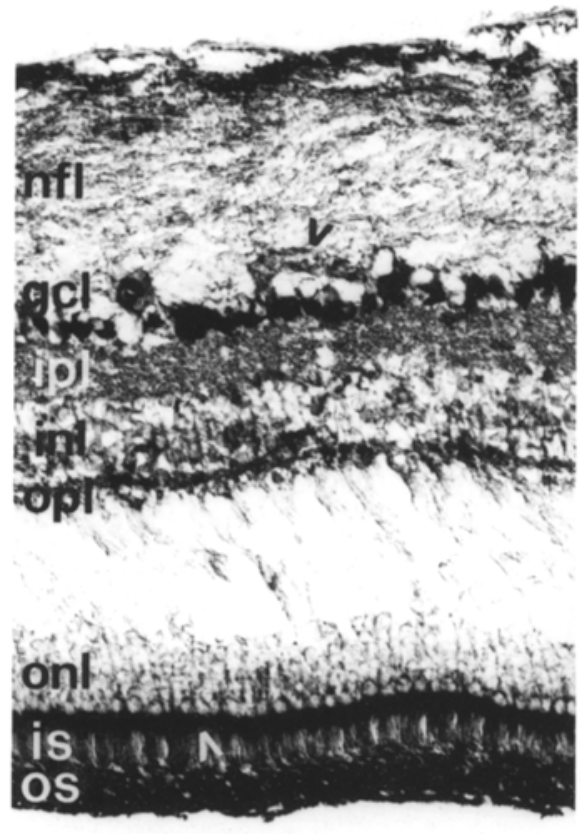

A

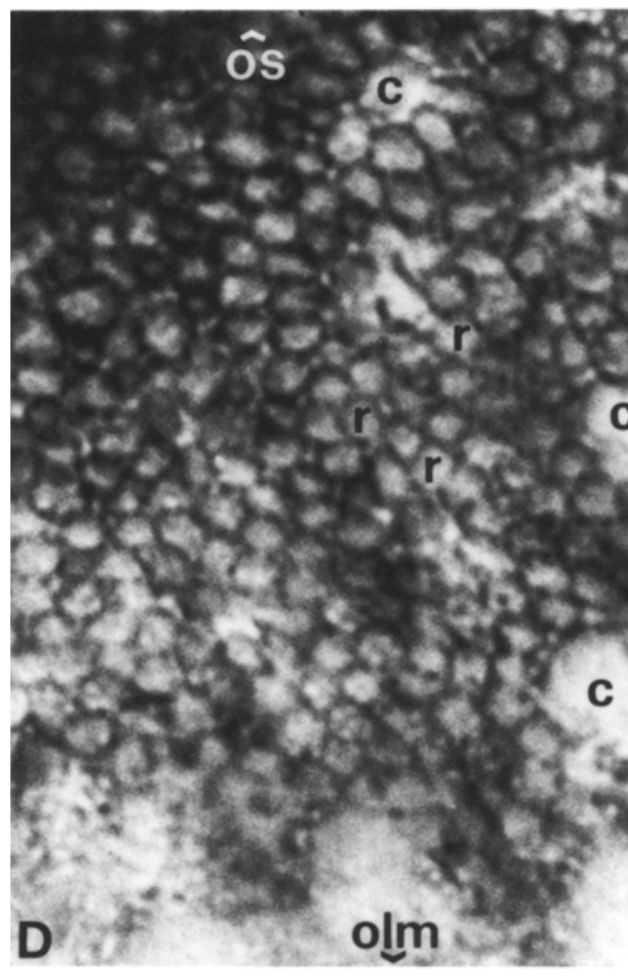

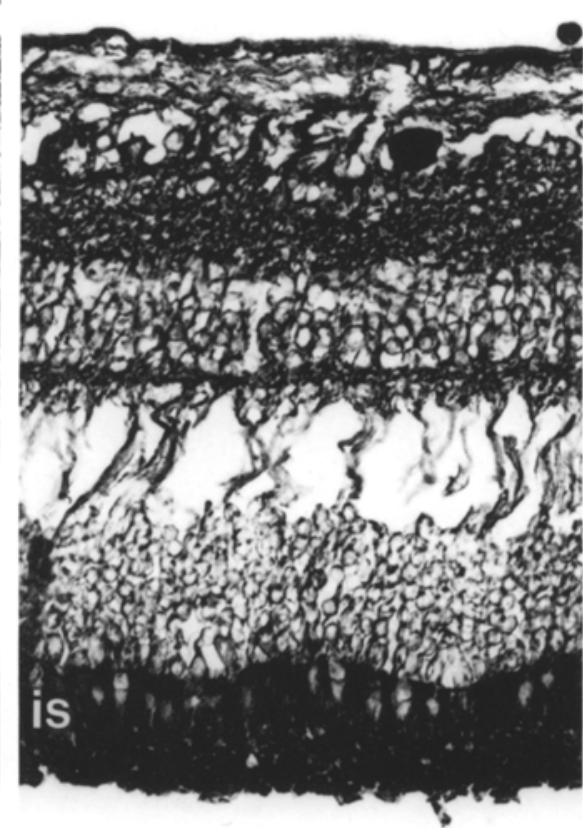

B

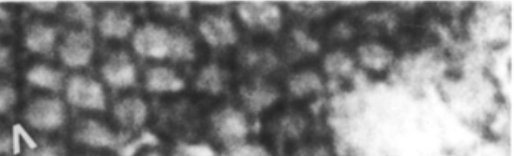

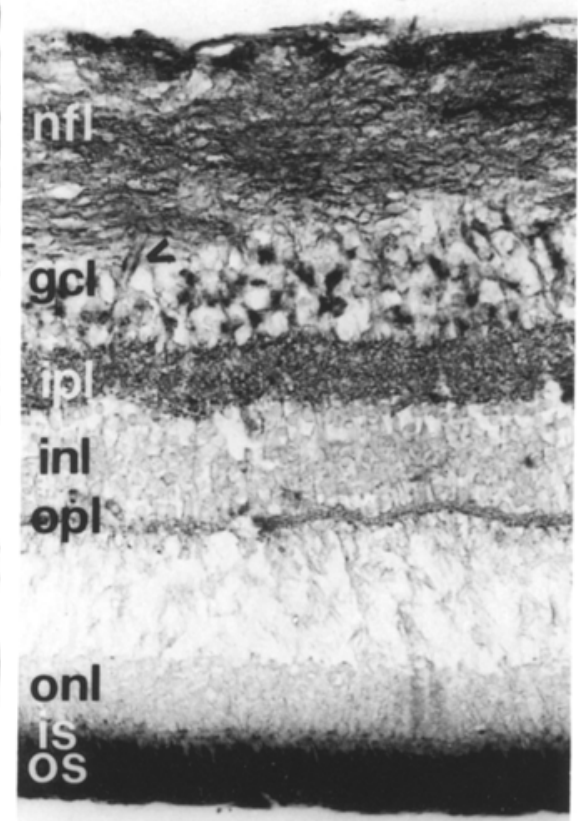

E

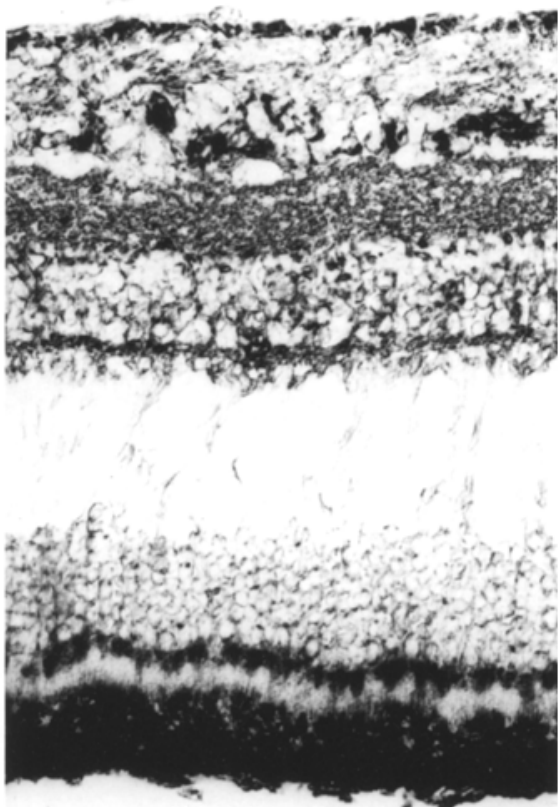

C

Fig. 1 A-E. Binding of mannosyl- and glucosyl-specific lectins to normal human retina (lectin cytochemical staining). A Without pretreatment, concanavalin A (ConA) binds to all retinal layers. Staining is most intense in the region of photoreceptor outer segments (os), in the outer limiting membrane where the fibre baskets of Müller's cells are situated (white arrowhead), and in neuronal cell bodies of the ganglion cell layer $(\mathrm{gcl})$. The endothelial cells of blood vessels (black arrowhead) are also labeled $\times 220$. B Pepsin treatment enhances binding of ConA to all retinal layers $\times 280$. C Binding on ConA to neuraminidase-treated sections is identical to that seen in untreated sections $\times 265$. D An oblique section through photoreceptor cells at the level of rod $(r)$ and cone $(c)$ inner segments. $O s$ and olm show the direction of photoreceptor outer segments and the outer limiting membrane, respectively. Both rods and cones are outlined with ConA, and weaker label is seen in their interior and in the interphotoreceptor matrix, which fills the gaps (white arrowhead) between photoreceptor cells $\times 2500$. E Lens culinaris agglutinin binds to all retinal layers and blood vessels (arrowhead) in a pattern reminiscent of that of ConA. The outer limiting membrane region, however, is weakly labeled $\times 220$. Nft nerve fiber; gcl ganglion cell; ipl inner plexiform; inl inner nuclear; opl outer plexiform; and onl outer nuclear layers; $O s$ photoreceptor outer and is inner segment 

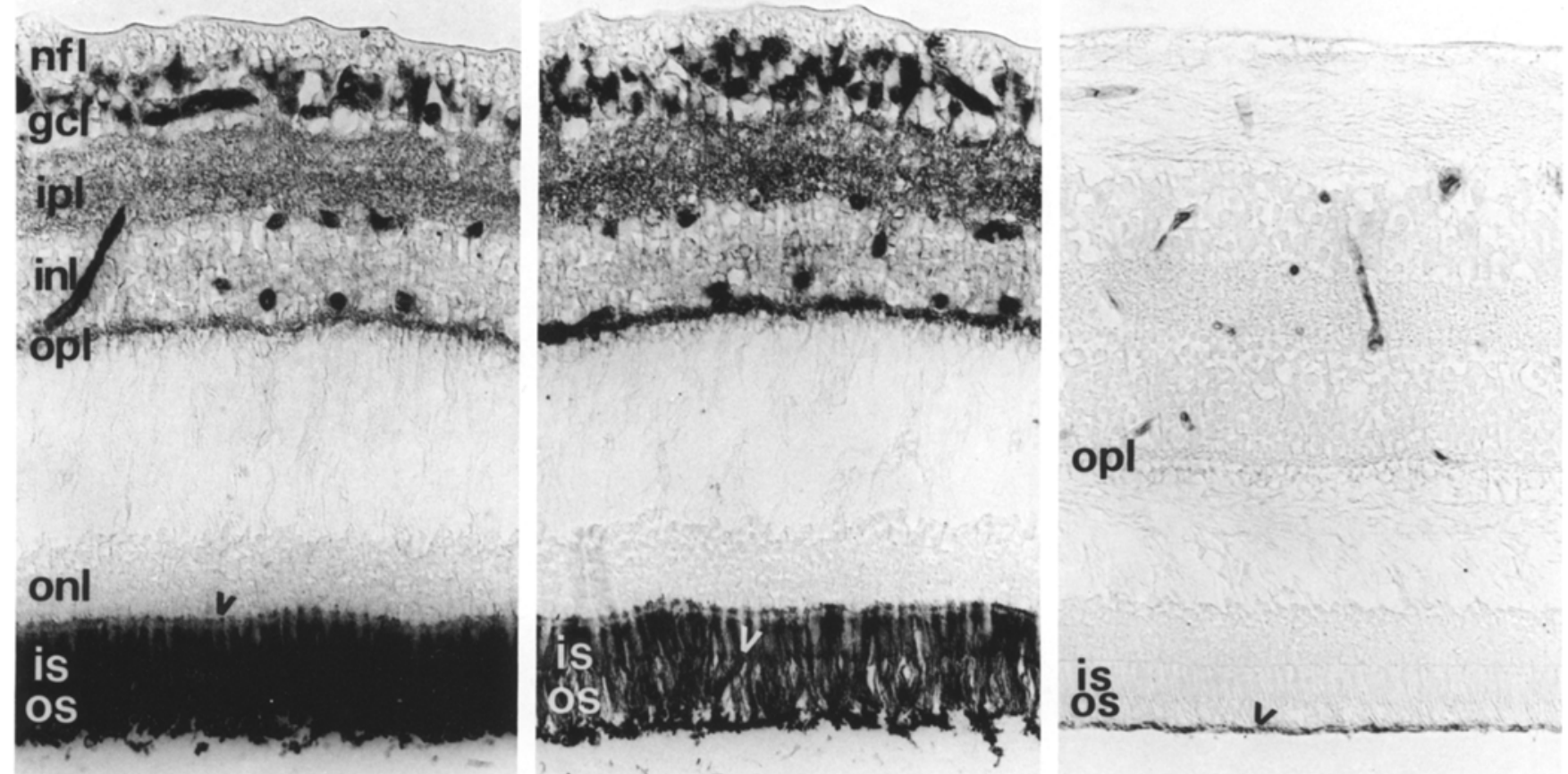

A

B

C

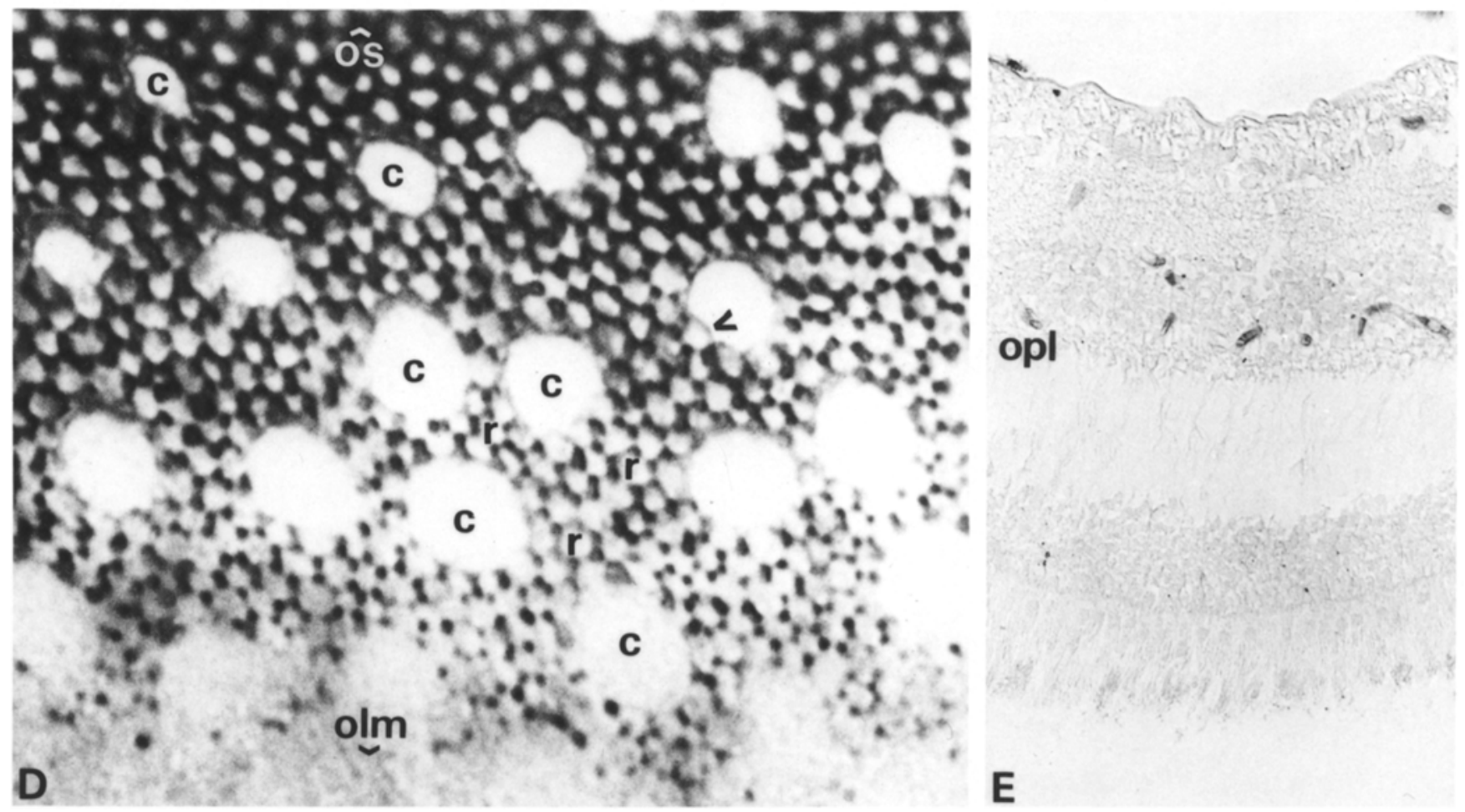

Fig. 2 A-E. Binding of $\mathrm{N}$-acetyl- $\beta$-D-glucosaminyl- and sialyl-specific lectins to normal human retina (lectin cytochemical staining). A Without pretreatment, wheat germ agglutinin (WGA) strongly labels the regions of photoreceptor outer (os) and inner (is) segments, the outer limiting membrane (arrowhead), neuronal cell bodies in the ganglion cell layer ( $\mathrm{gcl}$ ), and vascular endothelia in the inner retinal layers up to the outer plexiform layer $(o p l)$. The nuclear layers are weakly labeled $\times 240$. B After treatment with pepsin, reaction intensity is enhanced in all layers but photoreceptor outer (os) and inner (is) segment regions, which show reduced levels of binding $\times 240$. C After neuraminidase treatment, only vascular endothelial cells in the inner retinal layers bind WGA. Although some residual label remained in the photoreceptor outer segment region in some specimens, only pigment (arrowhead) from disrupted retinal pigment epithelium is observed here $\times 240$. D An oblique section through photoreceptor cells at the level of rod $(r)$ and cone $(c)$ inner segments. $O s$ and olm show the direction of photoreceptor outer segments and the outer limiting membrane, respectively. WGA mainly labels the gaps between the inner segments, as is best seen at the bottom and right sides of the photograph. This results in a faulty polyhedral outline of rods. The outlines of photoreceptor cells (arrowhead) are weakly visualised $\times 2500$. E Pokeweed mitogen binds only to vascular endothelial cells up to the outer plexiform $($ opl $)$ layer $\times 220$ 


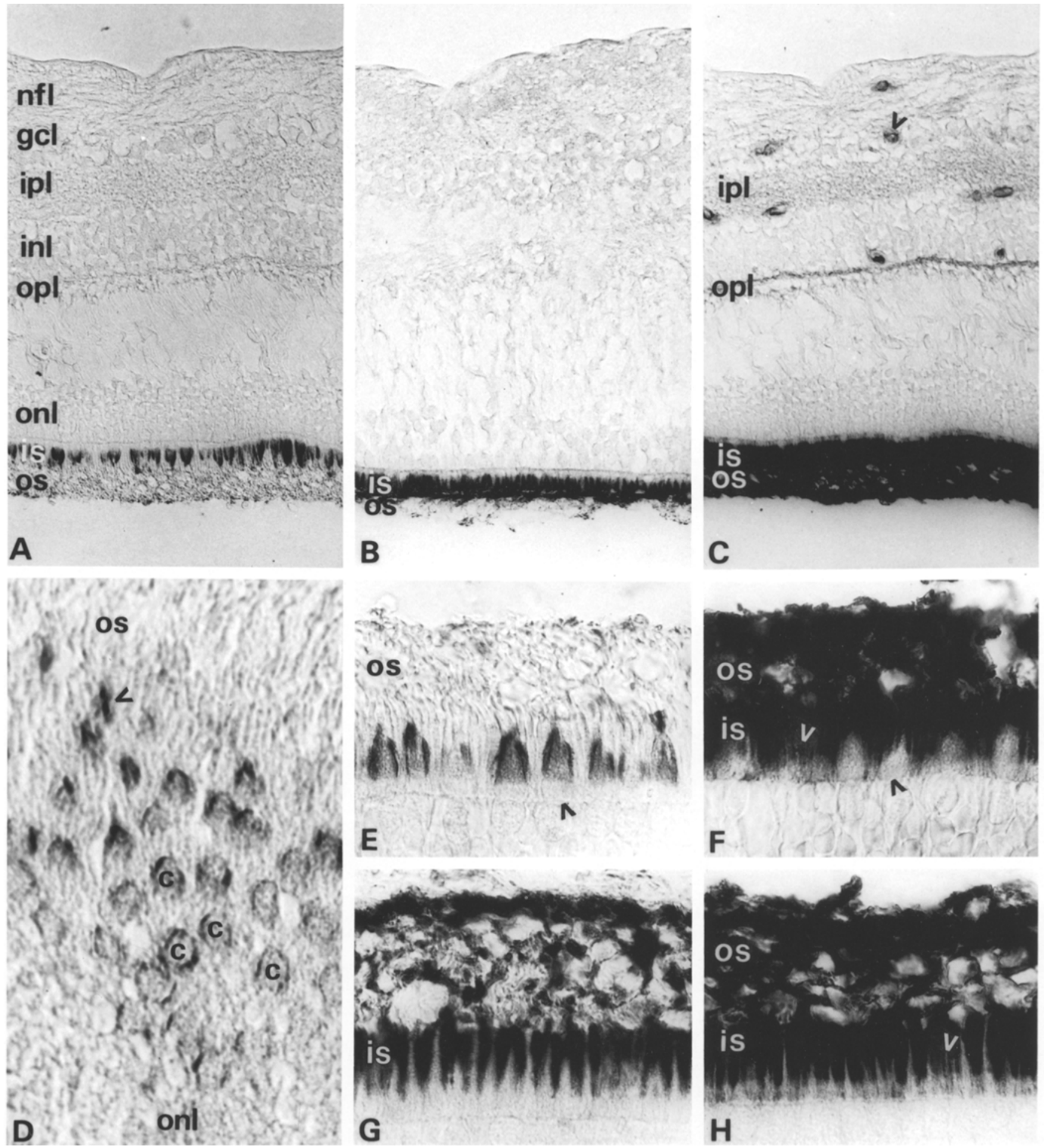

Fig. 3 A-H. Binding of the $\beta$-D-Gal $(1 \rightarrow 3)$-D-GalNAc-specific peanut agglutinin (PNA) to normal human retina (lectin cytochemical staining). A Without pretreatment, PNA specifically labels the regions of cone inner (is) and, less intensely, outer (os) segments $\times 250$. B After pepsin treatment, PNA binds more intensely to the inner segment (is) region, and it is sometimes difficult to localize it entirely to cones in the central retina $\times 250$. C After treatment with neuraminidase, PNA strongly labels the regions of both rod and cone outer $(o s)$ and inner (is) segments. It also labels both plexiform layers (ipl and $o p l$ ), and vascular endothelial cells (arrowhead), but not the nuclear layers $\times 250$. D An oblique section from the level of the outer nuclear layer (onl) to the level of the outer segments of photoreceptor cells $(o s)$, after pepsin treatment. Inner $(c)$ and outer (arrowhead) segments of cones are labeled, whereas rods are visible only because of phase contrast $\times 710$. E Cone inner segments are surrounded by positive reaction, which is absent in the immediate vicinity of the outer limiting membrane, the position of which is pinpointed by the arrowhead $\times 750$. F After neuraminidase treatment, this reaction reaches the outer limiting membrane (black arrowhead), and both rods (white arrowhead) and cones are labeled $\times 750 . \mathbf{G}$ and $\mathbf{H}$, corresponding photographs from the cone-rich paramacular area. The label is mainly localized to interphotoreceptor matrix $\times 750$. Positively labeled rods (arrowhead) are seen after treatment with neuraminidase 


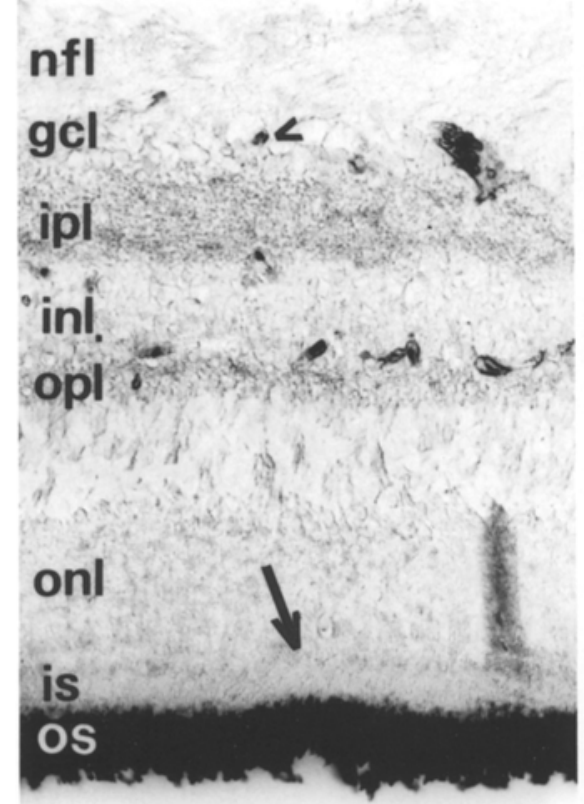

A
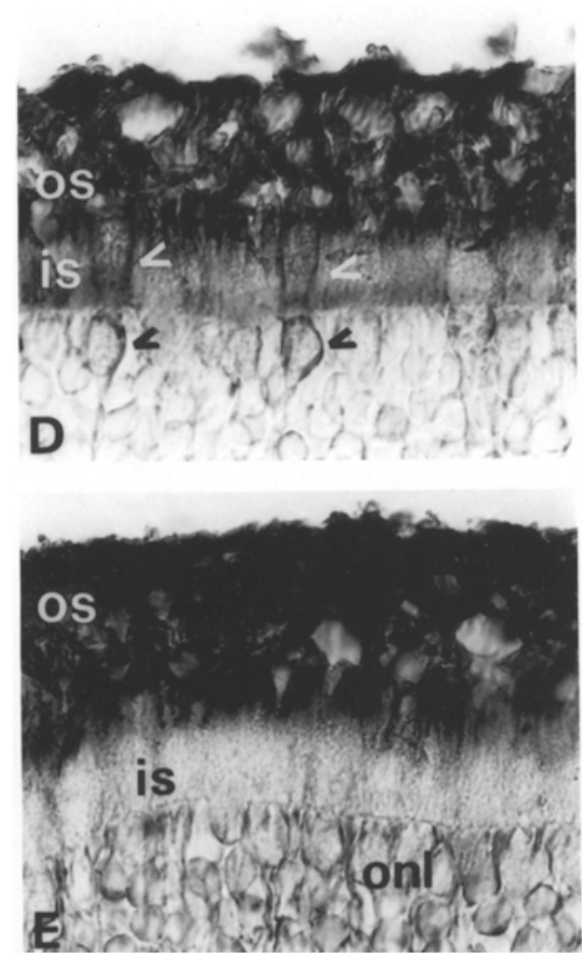

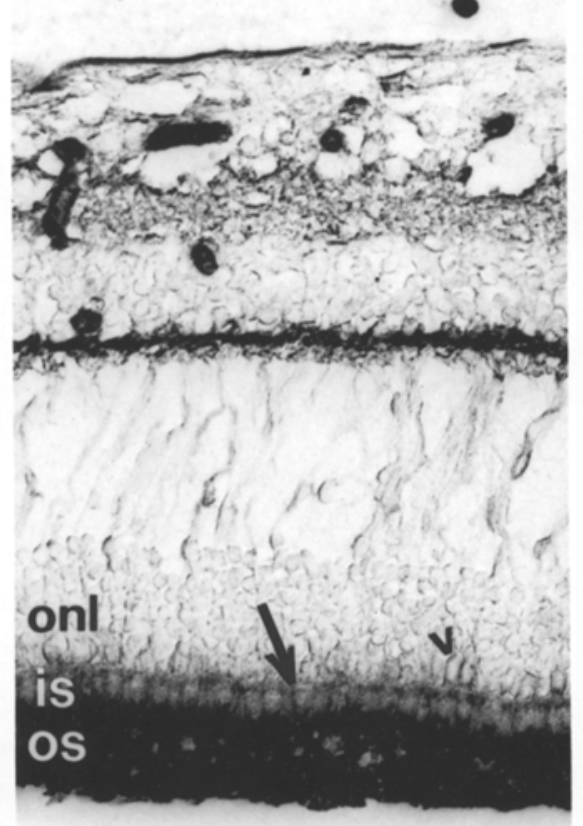

B

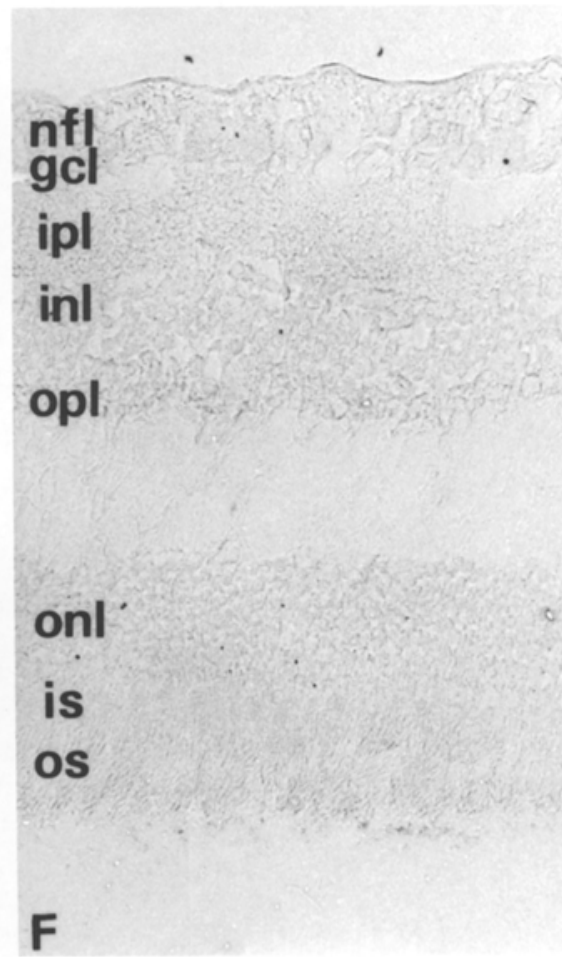

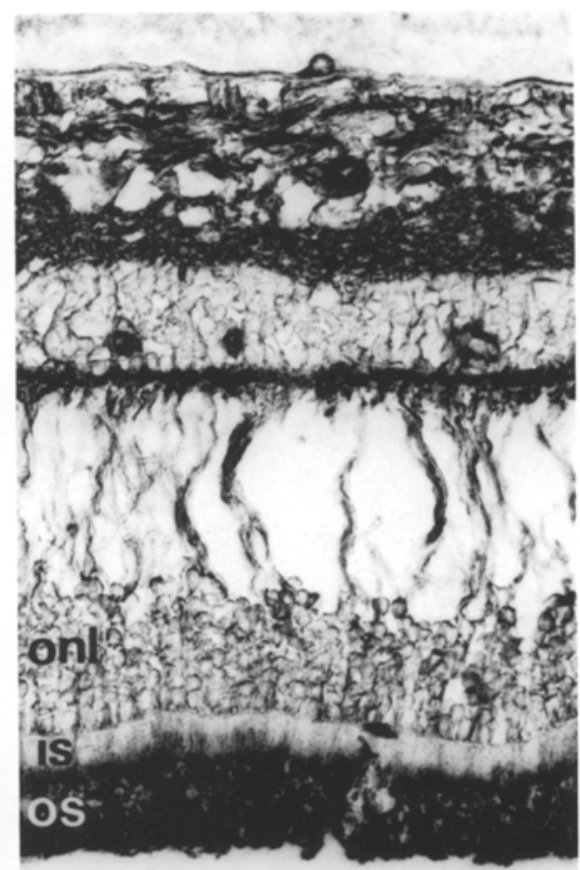

C

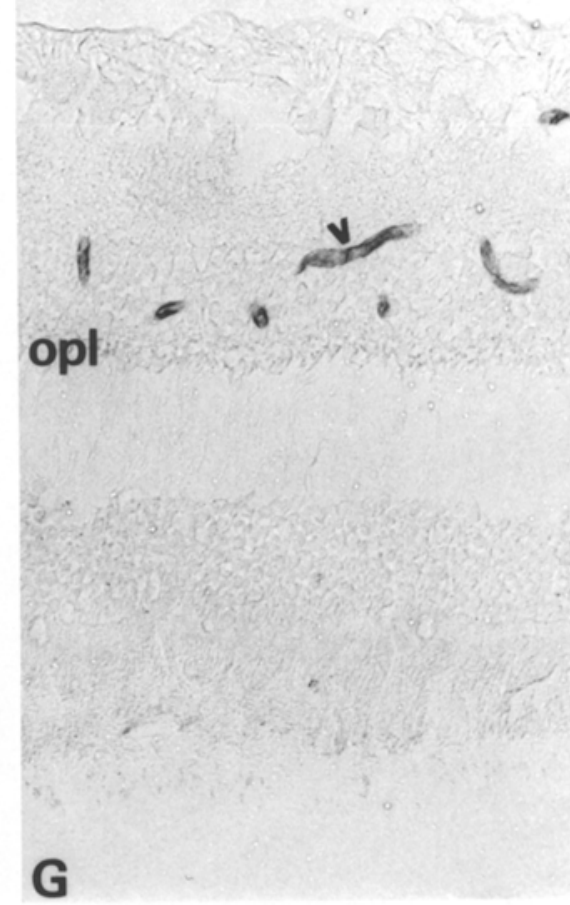

Fig. 4A-G. Binding of galactosyl-specific lectins to normal human retina (lectin cytochemical staining). A Ricinus communis agglutinin I (RCAI) binds strongly to the photoreceptor outer segment (os) region, and to vascular endothelial cells (arrowhead). Weak label is seen in both plexiform layers ( $i p l$ and $o p l$ ), and in the outer limiting membrane (arrow) region $\times 280$. B After pepsin treatment, RCAI binds more intensely to all these layers, especially to the outer limiting membrane (arrow), to photoreceptor cell inner segments (is), and to select cell bodies (arrowhead) adjacent to the limiting membrane $\times 280$. C In the neuraminidase-treated section, RCAI strongly labels all other retinal layers than photoreceptor inner segments (is). All cell bodies in the outer nuclear layer (onl) are positively labeled $\times 280$. D Photoreceptor cell layer after pepsin treatment. RCAI preferentially labels some cone inner segments (white arrowheads) and their cell bodies (black arrowheads). Other cell bodies are visible only because of phase contrast $\times 675$. E After neuraminidase treatment, the label in the inner segments $(i s)$ is reduced, but all elements in the outer nuclear layer (onl) bind RCAI $\times 675$. F Without pretreatment, Bandeiraea simplicifolia agglutinin I (BSAI) does not bind to any retinal layer $\times 230$. G After neuraminidase treatment, the vascular endothelial cells (arrowhead) are labeled with BSAI $\times 230$ 


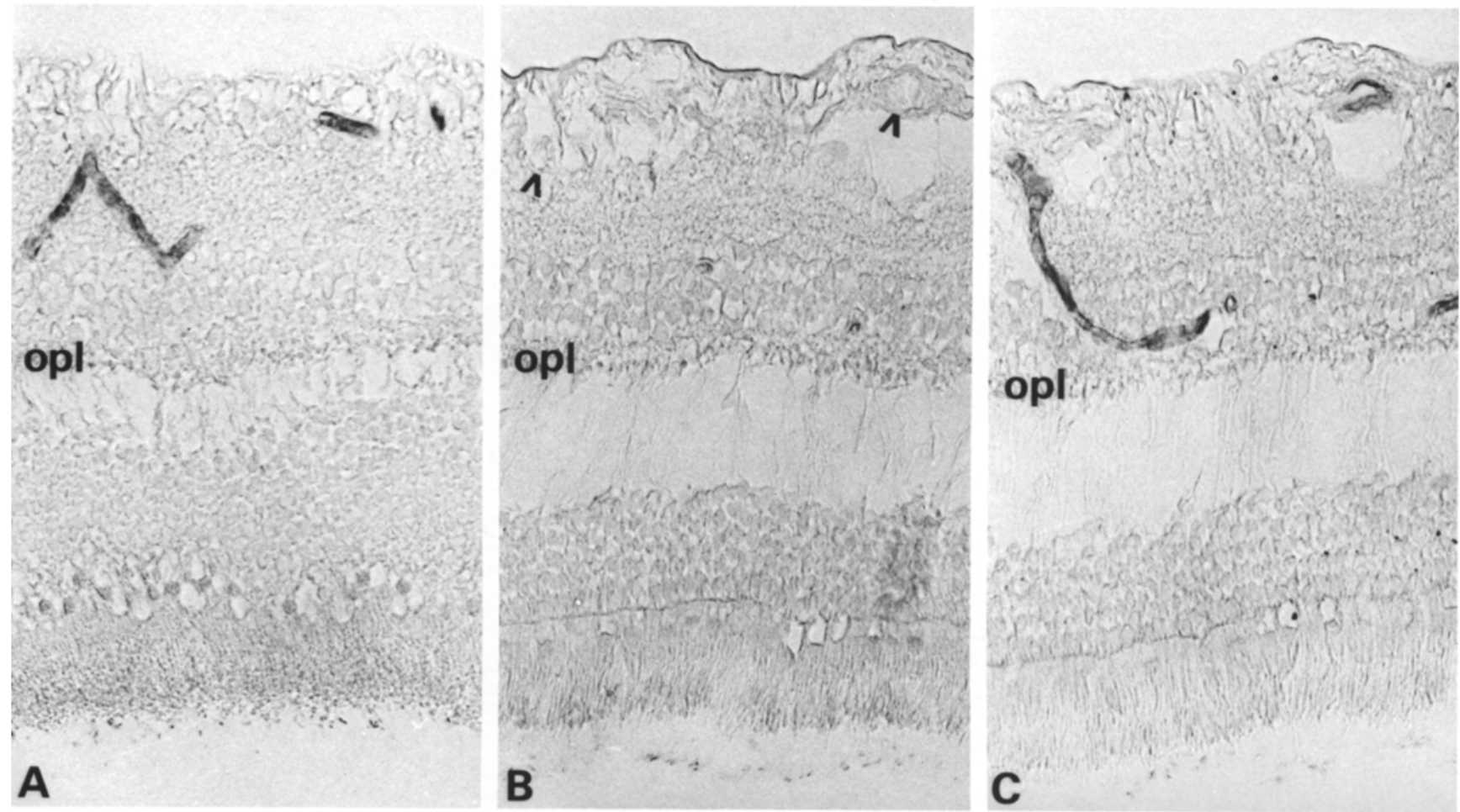

Fig. 5A-C. Binding of N-acetyl-D-galactosaminyl-specific Dolichos biflorus lectin (DBA) to normal human retina (lectin cytochemical staining). In all specimens, the positive reaction is present only in vascular endothelial cells in the inner retinal layers up to the outer plexiform layer $(o p l)$. A DBA reacts with endothelial cells from a patient belonging to blood group A without pretreatment $\times 280$. B Retina from a patient belonging to blood group O. DBA does not bind to the blood vessels (arrowheads) without pretreatment $\times 280$. C An adjacent section after neuraminidase digestion shows endothelial cells that are positively labeled with $\mathrm{DBA} \times 280$

cubation of RCAI with $\alpha$-lactose entirely abolished the positive reaction.

Bandeiraea simplicifolia agglutinin I (BSAI). In untreated and pepsin-treated sections, BSAI reacted only with goblet cells of the conjunctiva. The nonpigmented ciliary epithelium, corneal endothelium and neuroretina (Fig. 4F) were negative. After digestion with neuraminidase, however, the vascular endothelial cells in the retina were prominently labeled (Fig. 4G). This reaction was completely inhibited when BSAI was preincubated with $\alpha$-methyl-D-galactoside.

\section{$N$-acetylgalactosaminyl-specific lectins}

Dolichos biflorus agglutinin (DBA). Before enzymatic treatment, DBA strongly labeled the nonpigmented ciliary epithelium and goblet cells of the conjunctiva. It also reacted with the vascular endothelia in five specimens (Fig. 5A). Pepsin treatment did not alter this binding pattern. After digestion with neuraminidase, the vascular endothelial cells were positive in all specimens (Fig. $5 \mathrm{~B}, \mathrm{C}$ ). Interestingly, the specimens in which DBA labeled endothelial cells before neuraminidase treatment came from patients belonging to the blood group A. The positive reaction was absent after preincubation of DBA with N-acetyl-D-galactosamine.

Soybean agglutinin $(S B A)$. In untreated and pepsin-treated specimens, SBA bound only to the goblet cells of the conjunctiva. By contrast, after pretreatment with neuraminidase, all vascular endothelial cells were strongly labeled, but otherwise the retina remained negative. The corneal endothelium or the nonpigmented ciliary epithelium did not react with SBA. Preincubation of SBA with $\mathrm{N}$-acetyl-Dgalactosamine inhibited the lectin binding.

\section{Fucosyl-specific lectins}

Ulex europaeus agglutinin I (UEAI). UEAI reacted with vascular endothelial cells in untreated, pepsin-treated and neuraminidase-treated specimens, but did not label any other structures in the retina. UEAI also labeled upper layers of the conjunctival epithelium, but not the goblet cells or the corneal endothelium. Treatment with pepsin slightly enhanced the positive reaction, whereas neuraminidase did not expose any new binding sites. The positive reaction was absent after preincubation of UEAI with $\alpha-\mathrm{L}-$ fucose.

Lotus tetragonolobus agglutinin (LTA). In untreated and pepsin-treated sections any positive label was not seen. After neuraminidase digestion, the vascular endothelia and upper layers of the conjunctival epithelium became positively labeled. Binding of LTA was inhibitable by preincubation of the lectin with $\alpha$-L-fucose.

\section{Discussion}

In normal human retina, the agglutinins studied bound most prominently to the photoreceptor cell layer and to vascular endothelial cells (Table 2). The outer segment region strongly bound concanavalin A (ConA), as well as Lens culinaris (LCA), wheat germ (WGA). Ricinus commun- 
is (RCAI), and, after neuraminidase treatment, peanut (PNA) agglutinins, all of which also labeled the inner segment region and vascular endothelia in some extent. The positive reaction seen in the photoreceptor cell layer is probably not entirely due to labeling of cell membranes and cytoplasm, but partly resides in the interphotoreceptor matrix (Fong et al. 1984; Wood et al. 1984; Johnson et al. 1986). The results are in close agreement with previous studies, in which lectin binding to the retinae of eight other species has been studied using widely varying methodologies (Table 2). In particular, as reported for most (Table 2) but not all (Kawano et al. 1984b) species, PNA specifically labeled cones. One exception is that, in the mouse retina, the inner segment region preferentially binds many lectins (Blanks and Johnson 1983).

Pokeweed mitogen (PWM), and Bandeiraea simplicifolia (BSAI), Dolichos biflorus (DBA), soybean (SBA), Ulex europaeus (UEAI) and Lotus tetragonolobus (LTA) agglutinins labeled only vascular endothelial cells in the human retina, and pretreatment with neuraminidase was often required to demonstrate the positive reaction. These findings are also in general agreement with previous results (Table 2). Binding of DBA to the mouse (Blanks and Johnson 1983) and UEAI to the chicken (Bee $1982 \mathrm{a}$, b) neuroretina has been observed, which may represent methodological or true species differences.

The observed binding of agglutinins suggests, on the basis of their nominal carbohydrate specificities (Table 1), that glucose (ConA and LCA), mannose (ConA and LCA), $\beta$-galactose (PNA and RCAI), and N-acetyl-D-glucosamine (WGA) are present on glycoconjugates of the human neuroretina, whereas $\alpha$-galactose (BSAI), N-acetyl-D-galactosamine (DBA and SBA), and L-fucose (UEAI and LTA) are available for lectin binding only in vascular endothelial cells. These nominal specificities reflect the specific monoand oligosaccharides, that most effectively inhibit hemagglutination by the corresponding lectins in vitro. Other carbohydrate moieties on the same or adjacent glycoconjugates may, however, enhance or inhibit the binding of many lectins (Wu 1984). For example, it is known that radiolabeled fucose is incorporated into photoreceptor cells in some species (Bunt and Klock 1980; Saari and Bunt 1980), even though these glycoconjugates can not be detected by lectin cytochemical (Table 2) or lectin affinity chromatographical methods (Saari and Bunt 1980). This is also the reason why lectins with identical nominal specificities, such as ConA and LCA in the present study, do not necessarily give identical binding patterns.

There is indirect evidence to support the presence of $\mathrm{N}$-acetylneuraminic (sialic) acid in the human neuroretina. The prominent binding of WGA, which is specific for sialic acid in addition to $\mathrm{N}$-acetyl-D-glucosamine oligomers (Table 1), is greatly reduced after treatment of the human or monkey (Uehara et al. 1985) retina with neuraminidase, which destroys terminal sialic acid moieties. Pokeweed mitogen, specific only for oligomers of N-acetyl-D-glucosamine (Table 1), selectively labels retinal vascular endothelia, which are also labeled with WGA after neuraminidase treatment. These results do not, however, exclude the presence of $\mathrm{N}$-acetyl-D-glucosamine monomers in the retina which can be found at least on rhodopsin molecules (Fukuda et al. 1979; Liang et al. 1979). Finally, neuraminidase pretreatment substantially increases the binding of PNA and RCAI to human and monkey (Uehara et al. 1985) neu- roretina, due to removal of blocking sialic acid residues. In the mouse retina, the sialic- and glucuronic acid-specific Limulus polyphemus agglutinin (LPA) directly binds to photoreceptor cells and the nuclear layers (Blanks and Johnson 1983). These results are particularly interesting as it has been suggested that sialic acid might be an important signal in intercellular recognition in the retina (Uehara et al. 1985), especially as photoreceptor cells contain endogenous neuraminidase (Dreyfus et al. 1983).

The nature of the glycoconjugates binding lectins in the human retain remains to be determined. Gel electrophoretic and lectin blotting experiments have demonstrated, that ConA and WGA bind to rhodopsin (Bridges and Fong 1980) and to cone pigments (Fager and Fager 1978). Both ConA and WGA also detect higher molecular weight glycoproteins in photoreceptor cells (Molday and Molday 1979; Bridges and Fong 1980; Heth and Bernstein 1983), and PNA recognises a number of glycoconjugates with widely varying molecular weights in the retinae of different species (Johnson and Blanks 1982; Uehara et al. 1983 b; Hageman and Johnson 1984). In addition, if the assumption is true that carbohydrates are important to cellular recognition in the retina (McLaughlin and Wood 1980; Uehara et al. 1985), it should also be possible to find and characterise endogenous lectins from the retina. Finally, lectin cytochemistry might prove helpful in the field of human ophthalmic pathology, especially in diseases affecting photoreceptor cells, or leading to retinal neovascularisation.

Acknowledgements. We remain indebted to docent Ismo Virtanen for introducing us to the possibilities of lectin cytochemical methods and for providing several peroxidase-coupled and fluoresceincoupled lectins that were used in first preliminary experiments. The highly skilled technical assistance of Mrs. Marjatta Koikkalainen and Mrs. Pirkko Yliharju is deeply appreciated. This study was generously supported by a grant from the Emil Aaltonen Foundation.

\section{References}

Barondes SH (1984) Soluble lectins: a new class of extracellular proteins. Science 223:1259-1264

Bee JA (1982a) A cytochemical study of lectin receptors on isolated chick neural retina neurons in vitro. J Cell Sci 53:1-20

Bee JA (1982 b) Glycoconjugates of the avian eye: the development and maturation of the neural retain as visualized by lectin binding. Differentiation 23:128-140

Bhavanandan VP, Katlic AW (1979) The interaction of wheat germ agglutinin with sialoglycoproteins. The role of sialic acid. J Biol Chem 254:4000-4008

Blanks JC, Johnson LV (1983) Selective lectin binding of the developing mouse retina. J Comp Neurol 221:31-41

Blanks JC, Johnson LV (1984) Specific binding of peanut lectin to a class of retinal photoreceptor cells. A species comparison. Invest Ophthalmol Vis Sci 25:546-557

Bridges CDB (1981 a) Lectin receptors of rods and cones. Visualization by fluorescent label. Invest Ophthalmol Vis Sci 20:8-16

Bridges CDB (1981 b) Agglutination of isolated rod outer segments by lectins. Invest Ophthalmol Vis Sci 20:17-23

Bridges CDB, Fong S-L (1979) Different receptors for distribution of peanut and ricin agglutinins between inner and outer segments of rod cells. Nature 282:513-515

Bridges CDB, Fong S-L (1980) Lectins as probes of glycoprotein and glycolipid oligosaccharides in rods and cones. Neurochemistry $1: 255-267$

Bunt AH, Klock IB (1980) Comparative study of ${ }^{3} \mathrm{H}$-fucose incorporation into vertebrate photoreceptor outer segments. Vision Res 20:739-747 
Dreyfus H, Preti A, Harth S, Pellicone C, Virmaux N (1983) Neuraminidase in calf retinal outer segment membranes. J Neurochem 40:184-188

Etzler ME, Kabat EA (1970) Purification and characterization of a lectin (plant hemagglutinin) with blood group A specificity from Dolichos biflorus. Biochemistry 9:869-877

Fager LY, Fager RS (1978) Separation of rod and cone pigments from the chicken retina. Invest Ophthalmol Vis Sci (ARVO Abstr) 17:126

Fong S-L, Liou GI, Landers RA, Alvarez RA, Bridges CD (1984) Purification and characterization of a retinol-binding glycoprotein synthesized and secreted by bovine neural retina. J Biol Chem 259:6534-6542

Fukuda MN, Papermaster DS, Hargrave PA (1979) Rhodopsin carbohydrate. Structure of small oligosaccharides attached at two sites near the $\mathrm{NH}_{2}$ terminus. J Biol Chem 254:8201-8207

Goldstein IJ, Hayes CE (1978) The lectins: carbohydrate-binding proteins of plants and animals. Adv Carbohydr Chem Biochem $35: 127-340$

Goldstein IJ, Hammarström S, Sundblad G (1975) Precipitation and carbohydrate-binding specificity studies on wheat germ agglutinin. Biochim Biophys Acta 405:53-61

Hageman GS, Johnson LV (1984) Comparative analysis of peanut agglutinin-binding glycoproteins in vertebrate retinae. $\mathrm{J}$ Cell Biol 99:61 a

Hall MO, Nir I (1976) The binding of concanavalin A to the rod outer segments and pigment epithelium of normal and RCS rats. Exp Eye Res 22:469-476

Hayes CE, Goldstein IJ (1974) An $\alpha$-D-galactosyl-binding lectin from Bandeiraea simplicifolia seeds. J Biol Chem 249:1904-1914

Heth CA, Bernstein MH (1983) Characterization of bovine rod outer segment glycoproteins by SEM and SDS-PAGE. J Cell Biol [Suppl] 97:411 a

Hicks D, Molday RS (1985) Localization of lectin receptors on bovine photoreceptor cells using dextran-gold markers. Invest Ophthalmol Vis Sci 26:1002-1013

Hsu S-M, Raine L (1982) Versatility of biotin-labeled lectins and avidin-biotin-peroxidase complex for localization of carbohydrate in tissue sections. J Histochem Cytochem 30:157-161

Johnson LV, Blanks JC (1982) Biochemical characterization of cone-specific PNA-binding molecules in the retina. $\mathbf{J}$ Cell Biol [Suppl] 95:109a

Johnson LV, Hageman GS, Blanks JC (1986) Interphotoreceptor matrix domains ensheath vertebrate cone photoreceptor cells. Invest Ophthalmol Vis Sci 27:129-135

Kawano K, Uehara F, Sameshima M, Ohba N (1984a) Binding sites of peanut agglutinin in mammalian retina. Jpn J Ophthalmol 28:205-214

Kawano K, Uehara F, Sameshima M, Ohba N (1984b) Binding of peanut agglutinin in vertebrate retinal photoreceptors. J Eye $1: 260-262$

Kessimian N, Langner BJ, McMillan PN, Jauregui HO (1986) Lectin binding to parietal cells of human gastric mucosa. J Histochem Cytochem 34:237-243

Leathem A, Atkins N (1983) Lectin binding to formalin-fixed paraffin sections. J Clin Pathol 36:747-750

Liang C-J, Yamashita K, Muellenberg CG, Shichi H, Kobata A (1979) Structure of the carbohydrate moieties of bovine rhodopsin. J Biol Chem 254:6414-6418

Lis H, Sela B-A, Sachs L, Sharon N (1970) Specific inhibition by $\mathrm{N}$-acetyl-D-galactosamine of the interaction between soybean agglutinin and animal cell surfaces. Biochim Biophys Acta $211: 582-585$

Liu L, Layer PG, Gierer A (1983) Binding of FITC-coupled peanut-agglutinin (FITC-PNA) to embryonic chicken retinas reveals developmental spatio-temporal patterns. Dev Brain Res $8: 223-229$

Lotan R, Skutelsky E, Danon D, Sharon N (1975) The purification, composition, and specificity of the anti-T lectin from peanut (Arachis hypogaea). J Biol Chem 250:8518-8523
Matsumoto I, Osawa T (1969) Purification and characterization of an anti-H $(\mathrm{O})$ phytohemagglutinin of Ulex europeus. Biochim Biophys Acta 194:180-189

McLaughlin BJ, Wood JG (1977) The localization of concanavalin A binding sites during photoreceptor synaptogenesis in the chick retina. Brain Res 119:57-71

McLaughlin BJ, Wood JG (1980) The localization of lectin binding sites on photoreceptor outer segments and pigment epithelium of dystrophic retinas. Invest Ophthalmol Vis Sci 19:728-742

McLaughlin BJ, Wood JG, Gurd JW (1980) The localization of lectin binding sites during photoreceptor synaptogenesis in the chick retina. Brain Res 191:345-357

Molday RS, Molday LL (1979) Identification and characterization of multiple forms of rhodopsin and minor proteins in frog and bovine rod outer segment disc membranes. J Biol Chem $254: 4653-4660$

Nicolson GL, Blaustein J, Etzler ME (1974) Characterization of two plant lectins from Ricinus communis and their quantitative interaction with a murine lymphoma. Biochemistry 13:196-204

Nir I (1978) Visualization of intracellular concanavalin A binding sites in retinal photoreceptors. J Histochem Cytochem $26: 822-828$

Nir I, Hall MO (1979) Ultrastructural localization of lectin binding sites on the surface of retinal photoreceptors and pigment epithelium. Exp Eye Res 29:181-194

Nowak TP, Barondes SH (1975) Agglutinin from Limulus polyphemus. Purification with formalinized horse erythrocytes as the affinity adsorbent. Biochim Biophys Acta 393:115-123

Pereira MEA,Kabat EA (1974) Blood group specificity of the lectin from Lotus tetragonolobus. Ann NY Acad Sci 234:301-305

Saari JC, Bunt AH (1980) Fucosylation of rabbit photoreceptor outer segments: properties of the labeled components. Exp Eye Res 30:231-244

Schwechheimer K, Weiss G, Schnabel P, Möller P (1984) Lectin target cells in human central nervous system and the pituitary gland. Histochemistry 80:165-169

Uehara F, Sameshima M, Muramatsu T, Ohba N (1983a) Localization of fluorescence-labeled lectin binding sites on photoreceptor cells of the monkey retina. Exp Eye Res 36:113-123

Uehara F, Muramatsu T, Sameshima M, Ogata S-I, Ohba N (1983b) Identification of peanut agglutinin receptors in the monkey retina. Exp Eye Res 37:303-305

Uehara F, Muramatsu T, Sameshima M, Kawano K, Koide H, Ohba N (1985) Effects of neuraminidase on lectin binding sites in photoreceptor cells of monkey retina. Jpn J Ophthalmol $29: 54-62$

Virtanen I, Kariniemi A-L, Holthöfer H, Lehto V-P (1986) Fluorochrome-coupled lectins reveal distinct cellular domains in human epidermis. J Histochem Cytochem 34:307-315

Wood JG, Napier-Marshall L (1985) Differential effects of protease digestion on photoreceptor lectin binding sites. J Histochem Cytochem 33:642-646

Wood JG, Besharse JC, Napier-Marshall L (1984) Partial characterization of lectin binding sites of retinal photoreceptor outer segments and interphotoreceptor matrix. J Comp Neurol 228:299-307

Wu AM (1984) Differential binding characteristics and applications of $\mathrm{D}$ Gal $\beta 1 \rightarrow 3 \mathrm{D}$ GalNAc specific lectins. Mol Cell Biochem $61: 131-141$

Yokoyama K, Terao T, Osawa T (1978) Carbohydrate-binding specificity of pokeweed mitogens. Biochim Biophys Acta 538:384-396

Young NM, Leon MA, Takahashi T, Howard IK, Sage HJ (1971) Studies on a phytohemagglutinin from the lentil. III. Reaction of Lens culinaris hemagglutinin with polysaccharides, glycoproteins, and lymphocytes. J Biol Chem 246:1596-1601 